\title{
BOND STRENGTH OF HARD AND SOFT RELINING MATERIALS TO THERMOPLASTIC MONOMER FREE MICROCRYSTALLINE POLYMER (IN-VITRO COMPARATIVE STUDY)
}

\author{
Hala Mohamed Abd El Hameed* and Eman Husseiny Mohamed**
}

\begin{abstract}
Purpose analysis of bond strength of various denture relining materials to recently introduced thermoplastic monomer free semi rigid microcrystalline polymer and heat cured denture base materials.

Materials and methods: designed with cylindrical -shaped silicon patterns with dimensions $20 \mathrm{~mm}$ in length and $8 \mathrm{~mm}$ in diameter. Samples branched into four groups(20 samples for each group):

GI: heat cured acrylic resin samples with hard relining material, GII: heat cured acrylic resin samples with soft relining material. GIII: thermoplastic monomer free semi-rigid microcrystalline polymer (karadent) samples with hard relining material, GIV: thermoplastic monomer free semirigid microcrystalline polymer samples with soft relining material .

Tensile and shear bond strength of hard \& soft reliner to the two denture base materials examined by Instron Universal Testing Machine . Multiple group comparisons was assisted by one-way ANOVA test followed by T- test for pair wise comparisons to estimate any significant differences between groups. The tests deemed significant when $\mathrm{p} \leq 0.05$ and highly significant when $\mathrm{p} \leq 0.001$.
\end{abstract}

Results: Highly significant differences for both tensile and shear bond strength mean values was found between groups regarding the mean applied loads, P-value $\leq 0.001$. The t- test for comparison showed a extremely significant variance in the mean tensile \& shear bond strength between groups. Hard relining material showed greater mean values of both shear and tensile bond strength regarding the heat cured denture base material (GI) followed by karadent one (GIII) . The lowest mean values was found in soft relining material, specially that with karadent denture base material ( GIV) for both shear and tensile bond strength.

Conclusion: supporting on the results of this research, it might be terminated that newly introduced thermoplastic monomer free semi rigid microcrystalline polymer successfully accept relining specially with hard relining material .It overcomes the main problems of thermoplastic resins that can't accept relining

* Asist Prof. of Prosthodontics, Faculty of Dentistry Suez Canal University.

** Lecturer of Prosthodontics, Faculty of Dentistry Suez Canal University 


\section{INTRODUCTION}

One of the prime goals in fabricating complete dentures is to attain best fitting of denture base to the residual ridges. Gaps might occur between the denture fitting surface and the mucous membrane when a denture has been used for a protracted time. So, if the denture is relined, it used longer. There are two main choices for correction, the hard and soft reline. The necessary reason for relining is to regain perfect adaptability of denture base to underlying ridges and to permit equal load distribution. ${ }^{1}$

Soft lining materials used to produce a padding layer on the denture fitting surface to handle the traumatized Oral mucosa, bruxism, chronic soreness, atrophy or resorption of the residual ridge. Relatively non resilient and skinny mucous membrane, bony undercuts, and for non inheritable or inborn oral defects that required obturation. ${ }^{2}$

When soft lining materials get contact with fibromucous membranes in the transitional appliance after implant surgical procedures, they act as shock absorbers, rising the patient comfort and permit additional homogenized allocation of occlusal load. ${ }^{3}$

There are several issues associated with exploitation denture lining materials as, candidal colonization, porosity, loss of softness, poor tear strength and failure of bonding between the liner and denture base. Bond failure introduce a potential surface for bacterial development, plaque and calculus creation. Any favorable characteristics of a denture liner are not important without accurate bonding to denture base substances. ${ }^{4}$

Several characteristics affect bonding between lining materials and denture base, including water absorption, surface primer utilization and chemical composition of the denture base. ${ }^{5,6}$

Through the last century, polymethyl methacrylate (PMMA) denture base resin is the first substitutional for denture fabrication as a result of its minimal cost, amplitude esthetic characterization, and simple manipulation. Within the eighties, to cope allergic reactions and to revoke flasking, packing, and water bath polymerization, monomer free thermoplastic resins was introduced. ${ }^{7}$

It was documented that the magnitude of bond strength between the lining material and denture base influences the mechanical ferocity of the relined denture bases. ${ }^{8}$

So, investigation of shear and tensile bond strength of mercantile obtainable hard and soft denture relining materials to thermoplastic monomer free semi-rigid micro crystalline polymer denture base materials comparing to that with heat cured acrylic denture base resin was done.

\section{MATERIALS AND METHODS}

Eighty samples were designed with cylindrical -shaped silicon patterns, with dimensions $20 \mathrm{~mm}$ in length and $8 \mathrm{~mm}$ in diameter (Figure 1). ${ }^{9}$

Forty samples were constructed from conventional heat cure acrylic resin denture base materials. (Acrostone Heat Cure Denture base Material. Egypt). Another forty samples were constructed from thermoplastic monomer free semi-rigid micro crystalline polymer denture base materials (Karadent by TCS,INC,USA)

\section{Samples grouping}

Each group was divided per the character of relining material into: (1) twenty samples with denture hard reliner (Acrostone Heat Cure hard relining acrylic, Egypt) and (2) twenty samples with denture soft reliner (Acrostone Heat Cure soft relining acrylic. Cross linked. Egypt).

So, for statistical analysis samples divided mainly into four groups(20 samples for each group):

GI: Heat cured acrylic resin samples with hard relining material 
GII: Heat cured acrylic resin samples with soft relining material

GIII: Thermoplastic monomer free microcrystalline polymer (karadent ) samples with hard relining material

GIV: Thermoplastic monomer free microcrystalline polymer (karadent ) samples with soft relining material

\section{Preparation of heat cure samples}

The cylindrical -shaped silicon patterns has been wrapped with separating medium and inserted in the lower half of the flask that was crammed with mixed dental stone. When After stone was set, it painted with a separating medium, then the higher metal flask portion was adjusted on the lower one and filled with dental stone, air bubbles were eliminated by vibrations. Stone was allowed to harden before elimination of silicon pattern. The polymer and monomer of heat cure acrylic materials were mixed following the manufacturer's directions. Acrylic resin dough packed into the stone mold that created by removal of silicon patterns, then cured by long cycle $\left(70^{\circ}\right.$ for 9 hours). After samples curing and deflasking, they were finished and polished..$^{10}$ (Fig. 1 A\&B).

\section{Relining the prepared samples:}

Each finished sample was reoriented in their competent moulds.Four mm length was determined at the centre of the samples and has been sectioned.

Each tested hard and soft reliner prepared according to manufacturer's directions and packed in the barren middle portion of the cured samples $(8 \mathrm{~mm} \times 4 \mathrm{~mm})$. The samples in the closed flasks were permitted to cure ${ }^{9}$. After curing, the cylindrical samples with the reliner were encored from their flasks and by the help of diamond burs they were finished (Fig. 1 C -E).

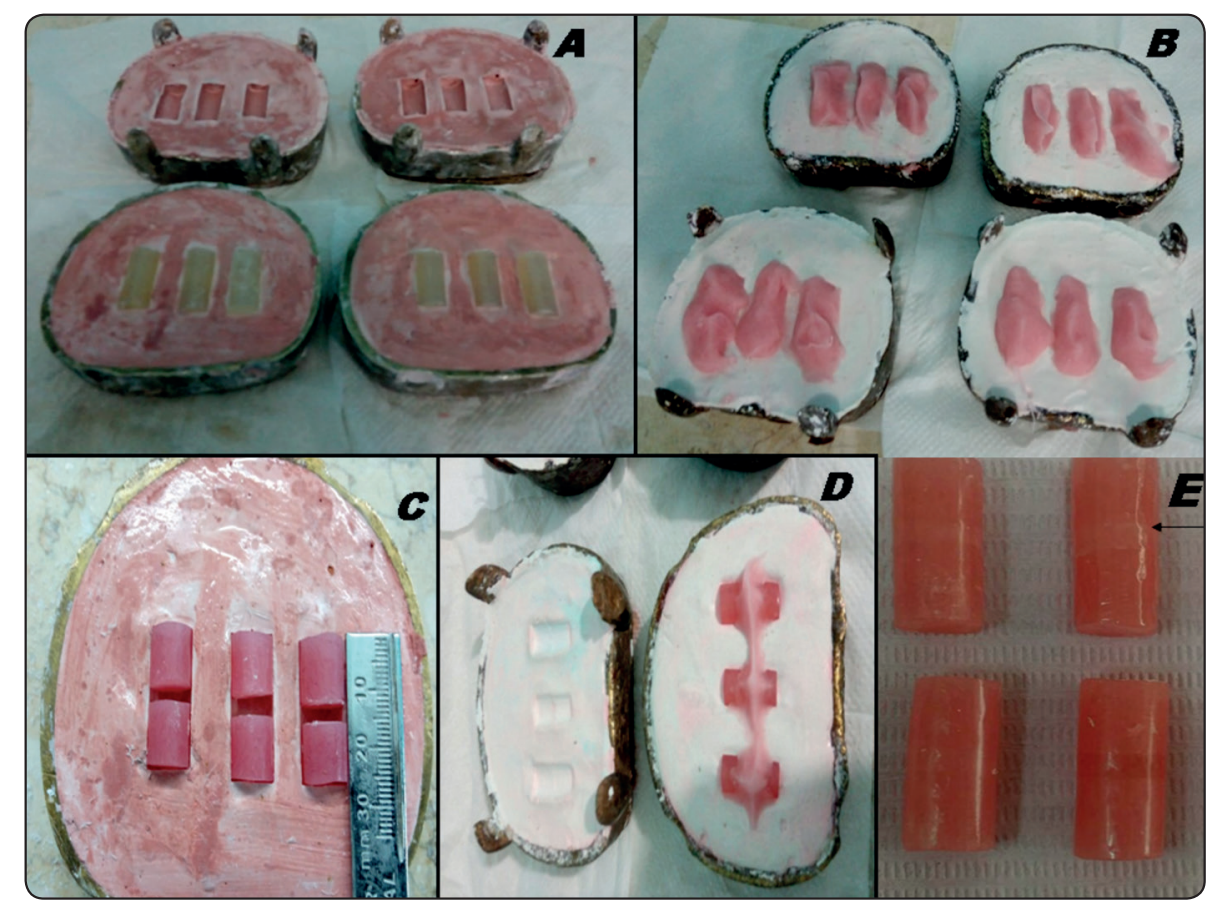

Fig.(1) (A, B) Preparation of heat cure samples (C-E) Relining the prepared samples 


\section{Preparation of thermoplastic monomer free mi- crocrystalline polymer samples.}

Teeming of gypsum paste into one of the two division of the flask was done. Investing the sprued wax patterns of the samples have been done in a vaselinezed aluminum flask.

After investment setting, the other half of the flask was assembled on the top of the deposed gypsum surface. Teeming the hard dental stone into the upper flask chamber was done to cover the wax pattern and sprues. The flask was immersed into warm water of a thermostatic container after setting of the gypsum. When the wax was boiled and the mould was created. Injection was carried out with the (Sabilex, Microinjection machine, Argentina) injector. The cartridge of injecting material (Sabilex, Flexi Acetal) was introduced into the heating cylinder. Preheating processes was then activated.

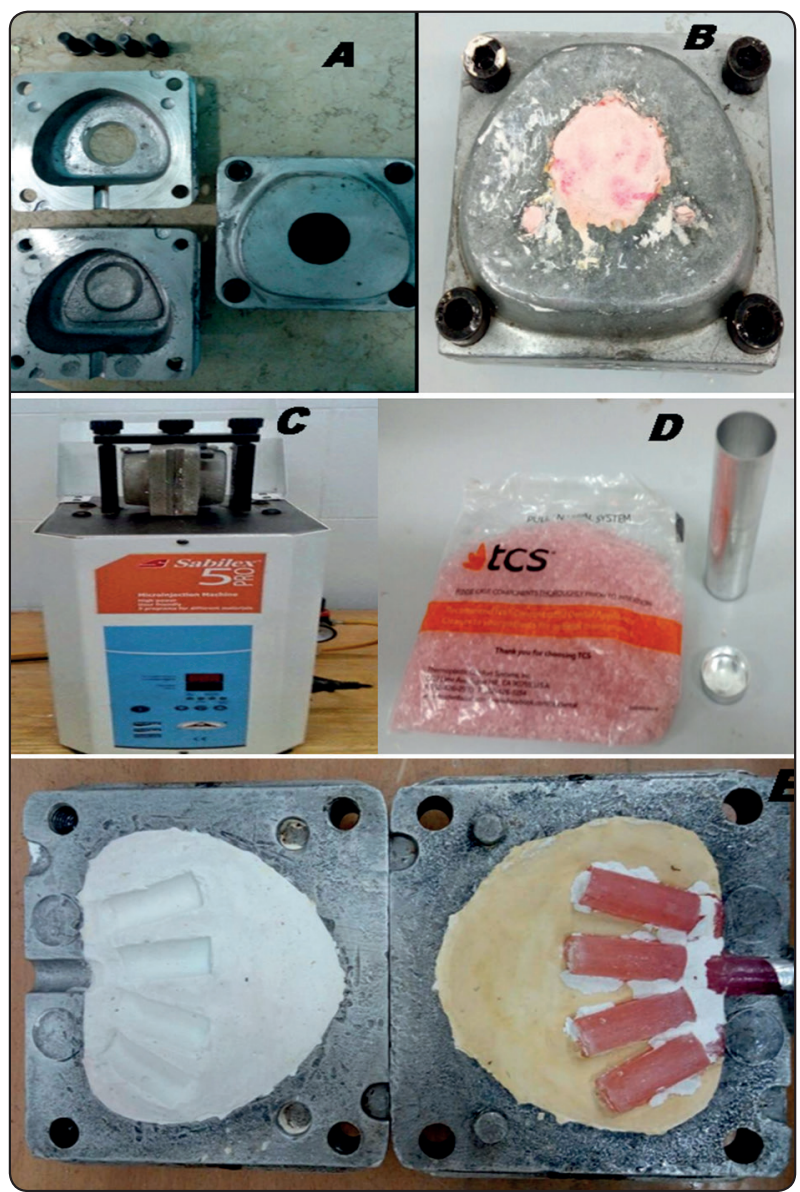

Fig. 2 (A-E).Preparation of thermoplastic monomer free microcrystalline polymer samples
The parts of the flask had been congregated and mounted by screws. The flask was inserted and secured in it's congruent position of the injecting unit. Squirting was launched after pressing the monitoring panel's key. The temperature was maintained at $280^{\circ}$ and a pressure of seven barat for twenty min consistent with the manufacturer's instructions. To plasticize the material in the cartridge to be injected into the flask. The cylinder was then moved and the cartridge separated. The flask was released and pulled out. The flask was left to chill down and investment was removed,the sprues were bring to an end, finishing and flourishing were carried out utilizing soft brushes and flourishing paste ${ }^{11}$ (Fig.2 A-E).

All samples were relined as mentioned before.

\section{Reliner bonding tests:}

Each cured samples with the interceded reliners were tested for measuring their tensile and shear bonding ferocity with the aid of Instron Universal Testing machine (3345 paradigm, England) that is managed digitally and contain a software system for test control and data conquest (Bluehill version 3.3). The tensile load $(5000 \mathrm{~N})$ was applied to the terminations of the samples (one half from all kinds) by a cross head speed of $1 \mathrm{~mm} / \mathrm{min}$ perpendicular to a joint surface until debonding of the tested material occurred. This force in Newton was registered by the system (Figure 4). Typically bond strength was calculated in Megapascals (Mpa), regarding the bonded surface area.

The second half of the samples subjected to shear load parallel to the denture base-reliner interface with cross head speed $(1 \mathrm{~mm} / \mathrm{min})$ using load cell capability $(5000 \mathrm{~N})$ of the Instron machine. The force required for bond failure was registered in Newton that divided by the guaranteed area to induce the shear bond strength in $\mathrm{Mpa}^{9}$ (fig.3A-C ).

(BS=F/SA).

$\mathrm{BS}=$ bond strength in Mpa

$\mathrm{F}=$ force by Newton

$\mathrm{SA}=$ surface area of bonded site $\left(\mathrm{mm}^{2}\right)$ 


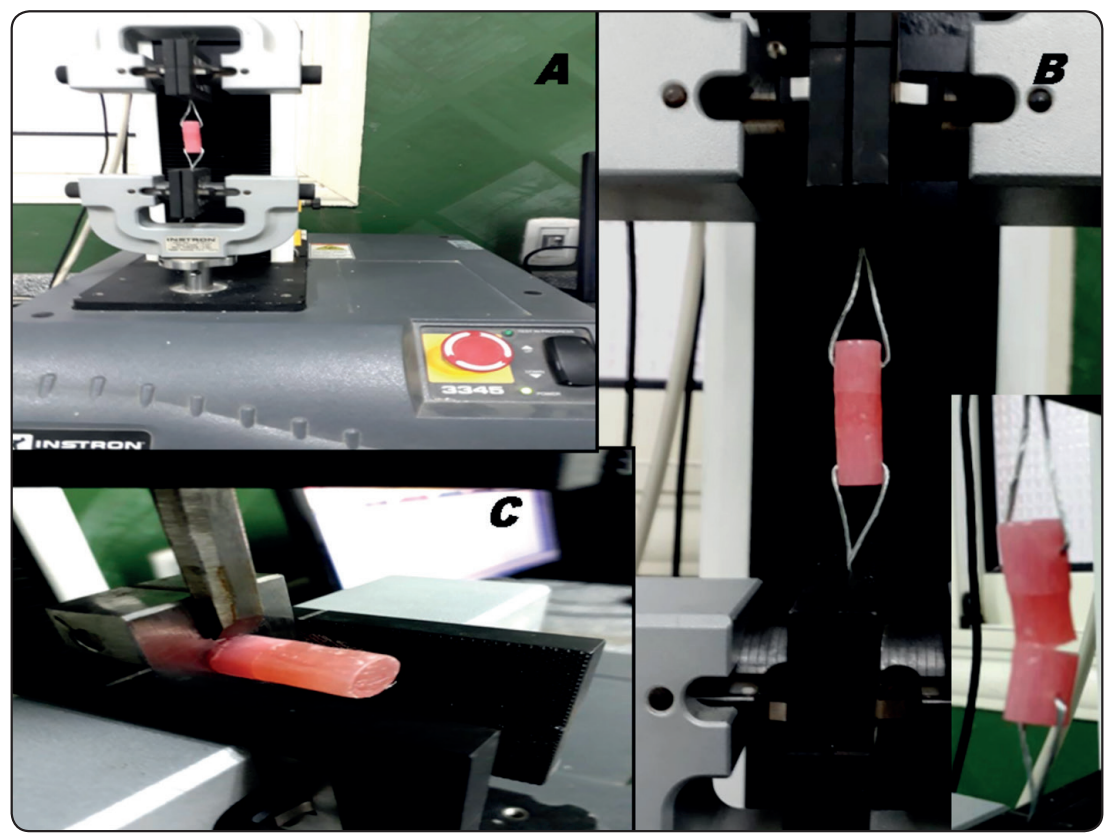

Fig. (3) A) Instron machine, B) reliner tensile bonding test. C) reliner shear bonding test.

\section{RESULTS}

Data ingress and analyses were accomplished through statistical software program. The data were offered as mean and standard deviations. One-way analysis of variance (ANOVA) at $95 \%$ dependability level used to survey variable effects. The test deemed significant at $\mathrm{p} \leq 0.05$ and highly significant at $\mathrm{p} \leq 0.001$.

$\mathrm{T}$ test for pair-wise comparison was used to deduct which group means were obviously different.

For ANOVA test, a great significant difference was noticed in tensile and shear bond ferocity between the tested groups in relation to the mean applied loads, $\mathrm{P}$-value $\leq 0.001$ (Table 1).
T-test for comparison manifested a highly significant variations in the mean strength values of both shear and tensile bond between groups. Hard relining material achieved the greatest mean strength values of both shear and tensile bond in favor to heat cured acrylic resin denture base material (GI) $(15.74 \pm 0.474,8.34 \pm 0.33)$ respectively, followed by karadent one (GIII) $(5.71 \pm 0.36,4.49 \pm 0.57)$ respectively. The lowest mean strength values was found in soft relining material, specially that with karadent denture base material( GIV) for both shear and tensile bond $(1.46 \pm 0.08,0.56 \pm 0.052)$ respectively (Table 2,3).

TABLE (1) One way ANOVA test showing mean values for shear \& tensile bond strength among different groups

\begin{tabular}{|c|c|c|c|c|c|c|}
\hline $\begin{array}{c}\text { Bond } \\
\text { strength }\end{array}$ & Source of Variation & $\begin{array}{c}\text { Sum of Squares } \\
(S S)\end{array}$ & $\begin{array}{c}\text { Degree of } \\
\text { Freedom }(d f)\end{array}$ & $\begin{array}{l}\text { Mean sum of } \\
\text { Squares }(M S)\end{array}$ & $\begin{array}{c}\text { Variance Ratio } \\
\qquad(F)\end{array}$ & $P$-value \\
\hline \multirow{2}{*}{ Shear } & Between Groups & 906.4994 & 6 & 151.0832 & 1389.115 & \multirow{2}{*}{$0.000 * *$} \\
\hline & Within Groups & 2.284007 & 21 & 0.108762 & 0.380668 & \\
\hline \multirow{2}{*}{ Tensile } & Between Groups & 258.3583 & 9 & 28.70648 & 196.0322 & \multirow{2}{*}{$0.000 * *$} \\
\hline & Within Groups & 2.635876 & 18 & 0.146438 & 0.439312 & \\
\hline
\end{tabular}


TABLE (2) t-test for pair-wise comparison in shear bond strength

\begin{tabular}{|c|c|c|c|}
\hline Groups & $\begin{array}{c}(X \pm S D) \mathrm{a} /(X \pm S D) \mathrm{b} \\
\text { (shear strength) }\end{array}$ & $\mathrm{t}$ - value & $P$-value \\
\hline GI / GII & $15.74 \pm 0.474 / 2.23 \pm 0.143$ & 61.27 & $0.000^{* *}$ \\
\hline GIII /GIV & $5.71 \pm 0.36 / 1.46 \pm 0.08$ & 32.16 & $0.000^{* *}$ \\
\hline GII /GIII & $2.23 \pm 0.143 / 5.71 \pm 0.36$ & 1.94 & $0.001^{* *}$ \\
\hline GI /GIII & $15.74 \pm 0.474 / 5.71 \pm 0.36$ & 43.325 & $0.000^{* *}$ \\
\hline GII /GIV & $2.23 \pm 0.143 / 1.46 \pm 0.08$ & 15.48 & $0.000^{* *}$ \\
\hline
\end{tabular}

TABLE (3) t-test for pair-wise comparison in tensile bond strength

\begin{tabular}{|c|c|c|c|}
\hline Groups & $\begin{array}{c}(X \pm S D) \text { a / }(X \pm S D) \mathrm{b} \\
\text { (Tensile strength) }\end{array}$ & t- value & $P$-value \\
\hline GI / GII & $8.34 \pm 0.33 / 1.49 \pm 0.084$ & 53.1 & $0.000^{* *}$ \\
\hline GIII /GIV & $4.49 \pm 0.57 / 0.56 \pm 0.052$ & 19.95 & $0.000^{* *}$ \\
\hline GII /GIII & $1.49 \pm 0.084 / 4.49 \pm 0.57$ & 14.1 .94 & $0.005^{* *}$ \\
\hline GI /GIII & $8.34 \pm 0.33 / 4.49 \pm 0.57$ & 12.7 & $0.000^{* *}$ \\
\hline GII /GIV & $1.49 \pm 0.084 / 0.56 \pm 0.052$ & 36.7 & $0.000^{* *}$ \\
\hline
\end{tabular}

$X=$ mean $\quad S D=$ standard deviation

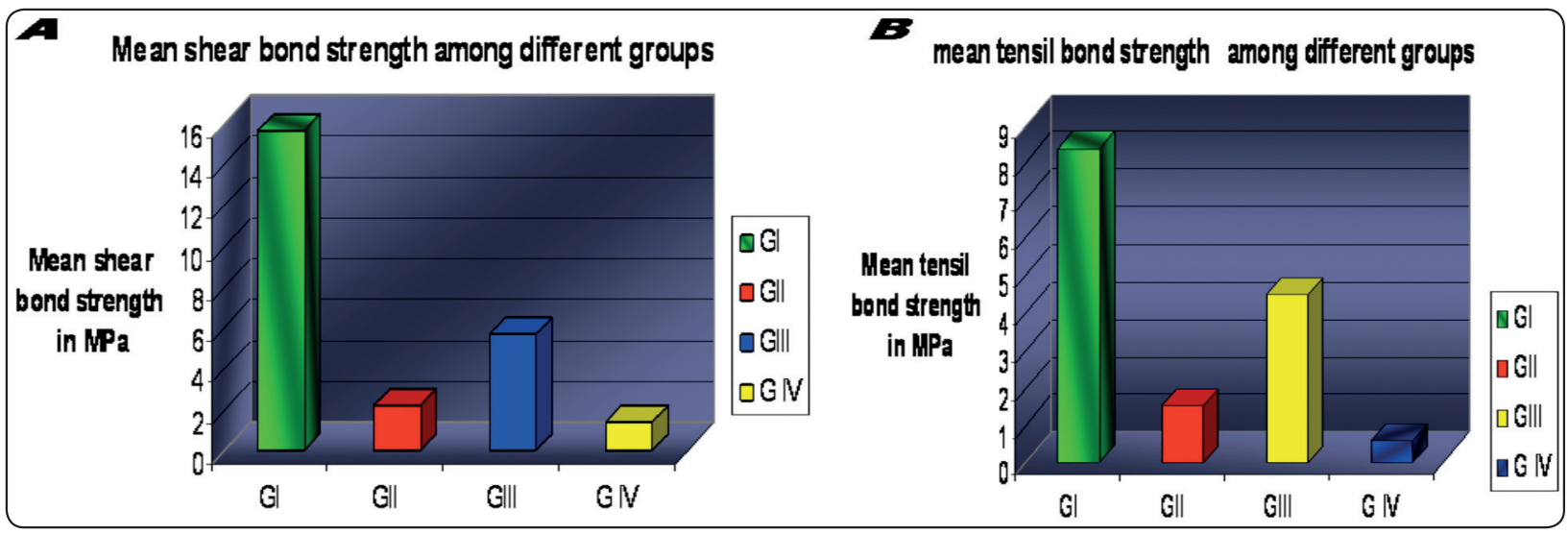

\section{DISCUSSION}

Poly (methylmethacrylate) continues to be the foremost commonly used denture base construction due to its superior esthetics, ease of processing \& repair and being economical. However, it has particular drawbacks like residual monomer allergic reactions, poor mechanical strength, decreased fatigue strength, brittle on impact, low hardness, elevated coefficient of thermal expansion, thermal shrinkage, poor color persistance of self-cured resins, porosity, crazing, and warpage. ${ }^{(12)}$

These properties cause several problems related to thermally polymerized acrylic against the thermoplastic version. Thermoplastic acrylic has quite impact resistance; however has sufficient tensile and flexural strength for a range of applications. The material is simple to regulate, handle and polish. Thermoplastic acrylic is obtainable in each tooth and gingival colours, and has both clearness and vitality for improved esthetics. Like most thermoplastic resins, acrylic resin is in addition strong, resists fracturing, and is flexible ${ }^{(13)}$

The microcrystalline polymer as a thermoplastic resin (Karadent by TCS, INC,USA) introduce several advantages over the traditional denture base materials, including highly aesthetic, Maximum strength and durability, No volume shrinkageexceptional fit, Minimal water absorption, lower residual monomer content so it act as alternatives to Poly Methyl Methacrylate in allergic patients.

Denture relining is defined as method employed to resurface the tissue aspect of denture. It precludes 
the requirement for creating new dentures for the patient providing him with denture has a relatively good condition. ${ }^{(14)}$

A tensile \& shear test method was advocted as it effects a simple load to the joint, that permits for comparison between distinct materials. Shear test method was additionally used during this study because it is similar to the masticatory load intraorally. ${ }^{(15)}$

Based on the result attained in the present study, hard relining material presented higher values of both shear and tensile bond strength in favor to heat cured denture base material, this can be due to the fact that the hard lining materials have a chemical composition similar to that of the PMMA denture base resins, the MMA monomer used for hard relining materials have penetrated into the denture base resin and polymerize with the reline acrylic resin. This makes the surface of denture base resin porous and a form of mechanical interlocking structure among the two materials would be established through this layer. ${ }^{(16)}$

This in agree with other researches suggesting that successful bonding among reline material and denture base resin depends on the effective penetration of monomer emanating from the polymerizing reline material into the denture base resin. This may explain the finding of higher values of both shear and tensile bond strength of Hard relining material to heat cured acrylic resin denture base material, followed by karadent that exhibits less porosity and no residual monomer. ${ }^{(17)}$

The lowest mean values of both shear and tensile bond strength to soft lining material specially that with karadent denture base material may be due the Plasticizer molecules content of the "liquid" element for acrylic-based denture soft lining materials that brings down the glass transition temperature and makes the material softer. However, such plasticizers don't seem to be"bound" inside the resin; so they drain out of the resin, that is one of the fundamental explanations for alterations within the mechanical properties of acrylic-based long-term soft denture linings. ${ }^{(18)}$

Moreover, the kind of denture base material, the planing of its surface with various-grit abrasive papers might have an effect on the results for bond strength. ${ }^{(19)}$

This study was completely laboratory based and in light of the fact that the most proper testing condition is the mouth, long-term clinical investtigations of this new material is required

\section{CONCLUSIONS}

The newly introduced thermoplastic monomer free semi rigid microcrystalline polymer successfully accept relining specially with hard relining material. It overcomes the main problems of thermoplastic resins that can't accept relining

\section{REFERENCES}

1- Hristov I, Pavlov B, Ivanova D, Hristov S. The Effect of relining on the fit and stability of complete dentures -An in vitro and in vivo study. J of IMAB, 2006; 12: 25-27

2- Machado AL, Breeding LC, Puckett AD. Effect of microwave disinfection on the hardness and adhesion of two resilient liners. J Prosthet Dent.2005;94:183-189.

3- León BL, Del Bel Cury AA, Rodrigues Garcia RC. Water sorption, solubility, and tensile bond strength of resilient denture lining materials polymerized by different methods after thermal cycling. J Prosthet Dent. 2005;93:282-287.

4- Meşe A. Bond strength of soft denture liners following immersion of denture cleanser. Biotechnology \& biotechnological equipment. 2006; 20: 184-191

5- Kulkarni RS, Parkhedkar R. The effect of denture base surface pretreatments on bond strengths of two long term resilient liners. J Adv Prosthodont. 2011;3:16-9

6- Nakhaei M, Dashti H, Ahrari F, Vasigh S, Mushtaq Sh, Shetty RM. The effect of different surface treatments and thermocycling on bond strength of a silicon -based denture liner to a denture base resin. The Journal of Contemporary Dental Practice 2016;17(2):154-159 
7- Tugut F, Coskun M E, Dogan D O, Kirmali O, Akin H. Tensile Bond Strength between Soft Liners and Two Chemically Different Denture Base Materials: Effect of Thermo cycling. J Prosthodont 2016;25 : 319-323

8- Wady AF, Machado AL, Vergani CE, Pavarina AC, GiampaoloET. Impact Strength of Denture Base and Reline Acrylic Resins Subjected to Long-Term Water Immersion. Braz Dent J 2011;22(1):56-61

9- Lau M,Amarnath G S Muddugangadhar, B C, SwethaM U, Ashok Kumar DasK A. Tensile and shear bond strength of hard and soft denture relining materials to the conventional heat cured acrylic denture base resin: An In-vitro study. Journal of International Oral Health 2014; 6:55-61

10- American Dental Association Specification No.12.Guide to dental materials and devices. 10th ed. Chicago; 1999. p.32.

11- Bortun C, Lakatos S, Sandu L, Negrutiu M, Ardelean L. Metal-free removable partial dentures made of thermoplastic materials. Timisoara Medical Journal. 2006; 56: $80-88$.

12- Nandal Sh, Ghalaut P, Shekhawat H, Gulati M S. New era in denture base resins: a review. Dental Journal of Advance Studies $2013 ; 1$
13- Negrutiu M, Sinescu C, Romanu M, Pop D, Lakatos S. Thermoplastic Resins for Flexible Framework Removable Partial Dentures. TMJ 2005; 55(3);295-99

14- Lau M, Amarnath GS, Muddugangadhar BC, Swetha MU and Kumar KAA. Tensile and shear bond strength of hard and soft denture relining materials to the conventional heat cured acrylic denture base resin: An In-vitro study. J Int Oral Health.2014:6(2):55-61

15- Ahmad F, Dent M, Yunus N. Shear bond strength of two chemically different denture base polymers to reline materials. J Prosthodont 2009;18:596-602

16- Hatim NA,AL-Omari AW. The Effect of Surface Treatment on the Transverse and Tensile Bonding Strength of Relined Acrylic Resin Denture Base (Part I). Al-Rafidain Dent J. 2013; 13(2): 202-210

17- Hasan RH. Shear Bond Strength of Hard Chairside Reline Material to Denture Base Material. Al-Rafidain Dent J. 2009; 9(2): 203-210.

18- Grzegorz Ch, Jarosław Z and Jacek K. Long-Term Soft Denture Lining Materials. Materials 2014, 7, 5816-5842

19- Mutluay M.M and Ruyter I.E. Evaluation of bond strength of soft relining materials to denture base polymers. Dent. Mater. 2007, 23, 1373-1381. 